$167: 1517$

27. Kileny P, Connelly C, Robertson L 1980 Auditory brainstem responses in perinatal asphyxia. Int J Pediatr Otorhinolaryngol 2:147

28. Lee SP, Cox LC 1982 Latency-intensity functions of the auditory brainstem evoked response in premature infants. Florida Language Speech Hearing Association J 3:15

29. Marshall RE, Reichert TM, Kerley SM, Davis H 1980 Auditory functions in newborn intensive unit patients revealed by auditory brainstem potentials. $\mathbf{J}$ Pediatr 96:731

30. McFarland WH, Simmons FB, Jones FR 1980 An automated hearing screening technique for newborns. J Speech Hearing Dis 4:495

31. Ment LR, Scott DT, Ehrenkranz RA, Rothman SG, Duncan CC, Warslaw WB 1982 Neonates of $<1,250$ grams birthweight; prospective neurodevelopmental evaluation during the first year post-term. Pediatrics 70:292

32. Mjoen S 1981 ABR in pediatric audiology. Scand Audiol Suppl 13:141

33. Morganstern N 1982 An infant hearing assessment program. Hearing Inst 33:44

34. Morgan A, Salle B 1980 A study of brainstem evoked responses in prematures. Acta Otolaryngol 89:370

35. Roberts JL, Davis H, Phon GL, Reichert TJ, Sturtevant EM, Marshall RE 1982 Auditory brainstem responses in preterm neonates: maturation and follow-up. J Pediatr 101:251

36. Salamy A 1981 The theoretical distribution of evoked brainstem activity in preterm, high-risk, and healthy infants. Child Dev 52:752

37. Salmy A, Somerville G, Patterson D 1982 The infant hearing assessment program. Hearing Aid J 35:10

38. Schulman-Galambos C, Galambos R 1975 Brainstem auditory-evoked responses in premature infants. J Speech Hearing Res 18:456
39. Schulman-Galambos C, Galambos R 1979 Brainstem evoked response audiometry in newborn hearing screening. Arch Otolaryngol 105:86

40. Shepard NT 1983 Newborn hearing screening using the Linco-Bennett Auditory Response Cradle: a pilot study. Ear Hearing 4:5

41. Simmons FB 1978 Identification of hearing loss in infants and young children Otolaryngol Clin N Am 11:19

42. Simmons, FB, McFarland WH, Jones FR 1979 An automated hearing screening technique for newborns. Act Otolaryngol 87:1

43. Simmons FB 1982 Comment on "hearing loss in graduates of a tertiary intensive care nursery." Ear Hearing 3:188

44. Sohmer H 1983 Neurologic disorders. In: Moore EJ (ed) Bases of Auditory Brain-stem Evoked Responses. New York, Grune and Stratton, pp 317-341

45. Stockard JE, Westmoreland BF 1981 Technical consideration in the recordin and interpretation of the brainstem auditory evoked potential for neonatal neurological diagnosis. Am J EEG Technol 21:31

46. Stockard JE, Stockard JJ 1983 Recording and analyzing In: Moore EJ (ed) Bases of Auditory Brain-stem Evoked Responses. New York, Grune and Stratton, pp 255-286

47. Weber BA 1982 Comparison of auditory brainstem response latency norms for premature infants. Ear Hearing 3:257

48. Worthington DW, Peters J 1980 Quantifiable hearing and ABR: paradox or error? Ear Hearing 5:281

49. Wright LB, Rybak LP 1983 Accuracy of Crib-O-Gram as screening test on high risk newborns. [Suppl 1] J Acoust Soc Am 73:79

50. Address correspondence to Dr. L. Clarke Cox, Department of Audiology, Cleveland State University, Cleveland, $\mathrm{OH} 44115$.

51. Received for publication August 15, 1983 .

\title{
Lipid Profiles and Lipase Activities in Children and Adolescents with Chronic Renal Failure Treated Conservatively or with Hemodialysis or Transplantation
}

\author{
KOHTARO ASAYAMA, ${ }^{(26)}$ HIROSHI ITO, CHIEKO NAKAHARA, AKIRA HASEGAWA, AND \\ KIYOHIKO KATO \\ Department of Pediatrics, School of Medicine, Keio University [K.A.] and Department of Pediatrics and Urology, \\ Tokyo Metropolitan Children's Hospital [H.I., C.N., A.H.], Tokyo, Japan and Department of Pediatrics, \\ Yamanashi Medical College [K.K.], Yamanashi, Japan
}

\section{Summary}

To elucidate the pathogenesis of hyperlipidemia in chronic renal disease in children and adolescents, we have measured serum triglyceride, total cholesterol, high density lipoprotein cholesterol (HDL-C) and activities of postheparin plasma lipoprotein lipase and hepatic triglyceride lipase (EC 3.1.1.3) in nine patients with transplants, and nine hemodialyzed and 18 conservatively treated patients with chronic renal failure. In 29 of 36 patients, serum insulin levels both in fasting and in response to oral glucose load were measured. The lipase activities were measured separately, utilizing antiserum against hepatic triglyceride lipase.

All groups of patients had hypertriglyceridemia. The patients with endogenous creatinine clearance less than $20 \mathrm{ml} / \mathrm{min} / \mathrm{m}^{2}$ had a low HDL-C level. The HDL-C level was correlated inversely with serum triglyceride level and positively with glomerular filtration rate. The lipoprotein lipase activities were low in patients with endogenous creatinine clearance less than $20 \mathrm{ml} / \mathrm{min} /$ $\mathbf{m}^{2}$. Although hepatic triglyceride lipase activities were not significantly low in any groups of patients, they were correlated with glomerular filtration rates in the conservatively treated patients with chronic renal failure. A defective triglyceride removal due to low lipase activities may contribute to uremic hypertriglyceridemia in these patients. On the other hand, patients with transplants had almost normal lipase activities and exhibited hyperinsulinemia; overproduction of triglyceride due to hyperinsulinemia may contribute to their hypertriglyceridemia.

\section{Abbreviations}

LPL, lipoprotein lipase

HTGL, hepatic triglyceride lipase

HD, hemodialysis

CRF, chronic renal failure

Tx, transplant

TG, triglyceride

TC, total cholesterol 
HDL-C, high density lipoprotein cholesterol $\mathrm{C}_{\mathrm{cr}}$, creatinine clearance

The relative roles of triglyceride overproduction and decreased clearance in the production of the hypertriglyceridemia associated with renal failure is still poorly defined $(19,22,23)$. In particular, the relative roles of hyperinsulinism and of the activities of hepatic and lipoprotein lipases in the production of hyperlipidemia remain to be elucidated $(1,2,7,10,12,16)$.

The present study has been designed to test the hypothesis that different mechanisms may contribute to the hyperlipidemia associated with conservatively treated chronic renal failure than affects those patients actively treated. Specifically, the study tests the hypothesis that changes in lipase activities and changes in insulin concentrations may differentially contribute to the hyperlipidemia in conservatively and actively treated patients.

Further, this study, confined to children, obviates the complication in interpretation of results reported in many previous studies $(5,9,13,14,23)$ in which patients with significant glucose intolerance have been included. Finally, to our knowledge, there is no prior study in children that is as exhaustive in defining the changes in lipid metabolism that are associated with renal failure. Particularly, there are little data on the changes in lipase activities.

In this study, we have measured by a selective specific immunochemical method postheparin plasma LPL and HTGL (EC 3.1.1.3) activities in three groups of patients; those conservatively treated and those treated with either hemodialysis or transplantation. These activities have been compared with measurements of total serum triglyceride and cholesterol, HDL-cholesterol, and insulin responses to oral glucose challenge. The data suggest differing etiological factors are associated with anomalies in lipid profiles in these different groups.

\section{MATERIALS AND METHODS}

Nine post-transplant patients and 27 patients with various degrees of impaired renal function were studied. The underlying renal diseases were chronic glomerulonephritis in 22 cases, hypoplastic kidney in seven, and other causes in seven. None had hypoalbuminemia $(<2.5 \mathrm{~g} / \mathrm{dl})$, diabetes mellitus, or other endocrine diseases known to affect lipid metabolism. None was excessively over- or underweight. They were divided into five groups as follows. The first group consisted of transplant recipients, the second was patients on maintenance $\mathrm{HD}$, the remaining patients had chronic renal failure which was mild (CRF I), moderate (CRF II), or severe (CRF III). There were nine (seven males and two females) Tx patients in the study with endogenous creatinine clearance $\left(\mathrm{C}_{\mathrm{cr}}\right)$ of more than $20 \mathrm{ml} / \mathrm{min} / \mathrm{m}^{2}$. Transplantation had been performed 3 to 35 (mean 21) months before this study. Patients were under no dietary restriction, but receiving immunosuppressive therapy with cytotoxic agents and methylprednisolone $(0.41 \pm 0.10 \mathrm{mg} / \mathrm{kg} /$ day $)$.

There were nine patients (four males and five females) on HD for 1 to 82 (mean 44) months. Dialysis was performed for 4 to 5 $\mathrm{h}$ three times weekly using Hollow Fiber Kidney (Asahi Medical, Kurare, Tokyo, Japan). The dialysate contained $0.2 \%$ dextrose and $33 \mathrm{mM}$ acetate. The dose of heparin during HD was 20 to $25 \mathrm{U} / \mathrm{kg}$ (IV bolus) followed by a constant infusion of 20-25 U/ $\mathrm{kg} / \mathrm{h}$. To minimize the effect of this heparin administration, these patients were studied 3 days after the last HD. They were maintained on a constant renal diet, containing $90 \%$ of the recommended daily caloric allowance for children, with a protein intake of between 1.35 to $2.0 \mathrm{~g} / \mathrm{kg} / \mathrm{day}$, depending on the age of the patient.

There were 18 (13 males and five females) conservatively treated patients with CRF. They were assigned to CRF I, CRF II, and CRF III, according to the degree of renal insufficiency (CRF I, $\mathrm{C}_{\mathrm{cr}} \geqq 20 \mathrm{ml} / \mathrm{min} / \mathrm{m}^{2} ; \mathrm{CRF}$ II, $6 \leqq \mathrm{C}_{\mathrm{cr}}<20 ; \mathrm{CRF}$ III, $\mathrm{C}_{\mathrm{cr}}$ $\leqq 5 \mathrm{ml} / \mathrm{min} / \mathrm{m}^{2}$ ). These patients were maintained on a constant renal diet again containing $90 \%$ of the recommended daily caloric allowance for children, with a protein intake of between 1.0 and $1.3 \mathrm{~g} / \mathrm{kg} /$ day. Twenty-two nonobese, normal children (13 males and nine females), ages 6 to 15 years, served as controls. With the exception of one female Tx patient of 19 years, all patients were under 18 . The mean age was $11 \pm 1$ years. Within this group of patients, no independent age-related correlation was noted with any of the indices measured. This result is supported by data indicating that changes in serum lipoprotein profile are small prior to completion of sexual maturation (15). Written informed consent was obtained from the parents of each study and control subject.

Blood samples were drawn after an overnight fast. Serum samples obtained before heparin administration were used for the determination of TG, TC and HDL-C. Blood samples for the lipase assay were drawn after IV administration of $10 \mathrm{U} / \mathrm{kg}$ body weight of heparin (Novo, Denmark), into tubes containing a final EDTA concentration of $0.1 \%$. The plasma was immediately separated at $4^{\circ} \mathrm{C}$ and stored at $-80^{\circ} \mathrm{C}$ until enzyme activities were measured. Twenty-nine of the 36 patients underwent the oral glucose tolerance test $(1.75 \mathrm{~g} / \mathrm{kg}$ ideal body weight administered as $33 \%$ glucose solution) on a different day. Glucose tolerance was normal in all subjects studied, judging from the criteria recommended by the Research Committee of Juvenile Diabetes (the Ministry of Health and Welfare, Japan) (11).

The activities of postheparin plasma LPL and HTGL were measured according to the immunochemical method described by Murase et al. (17), utilizing antiserum against the latter enzyme. The antiserum was prepared by immunizing a rabbit (four times at 2-week intervals) with HTGL, which was partially purified by heparin-Sepharose affinity chromatography from 50 $\mathrm{ml}$ of human postheparin plasma. Figure 1 shows the specificity of the antiserum. The antiserum inactivated the activity of HTGL purified on the affinity column almost completely, whereas it had no effect on the purified LPL. The two lipase activities in postheparin plasma were separately measured using this antiserum. Lipolytic activity was assayed as follows. The substrate was a mixture of $2 \mu \mathrm{Ci}$ of glycerol tri $\left[1-{ }^{14} \mathrm{C}\right]$ oleate (Amersham/Searle Corp., Arlington Heights, IL), $0.133 \mathrm{~g}$ triolein (Sigma Chemical Co., St. Louis, MO) $0.9 \mathrm{ml}$ of $4 \%$ bovine serum albumin solution ( $\mathrm{pH} 8.6$ ), $0.9 \mathrm{ml}$ of $1 \%$ Triton $\mathrm{X}-100$, and 10.2 $\mathrm{ml}$ of $0.2 \mathrm{M}$ Tris- $\mathrm{HCl}$ buffer ( $\mathrm{pH} \mathrm{8.6)}$. The mixture was sonicated on ice with an ultrasonic disruptor (UR-200P, Tomy Seiko Co., Tokyo) for $3 \mathrm{~min}$ at 80 watts. This substrate $(0.4 \mathrm{ml})$ was mixed with pooled human plasma $(0.1 \mathrm{ml})$ and $0.2 \mathrm{M}$ Tris- $\mathrm{HCl}$ buffer containing $4 \%$ bovine serum albumin $(\mathrm{pH} 7.4)(0.48 \mathrm{ml})$, and incubated with $20 \mu \mathrm{l}$ of postheparin plasma for $30 \mathrm{~min}$ at $37^{\circ} \mathrm{C}$. Free fatty acid liberated by hydrolysis was extracted and the radioactivity was counted by the method of Schotz et al. (24). The enzyme activity was expressed as micromoles of $\mathrm{FFA} / \mathrm{ml}$ / h. The inactivation of HTGL activity was carried out by incubating postheparin plasma with antiserum for $60 \mathrm{~min}$ at $4^{\circ} \mathrm{C}$. The remaining lipolytic activity (LPL) was assayed, and the HTGL activity was then obtained by subtracting this value from total lipase activity.

From the result shown in Figure 1, the antiserum in an amount of one-fourth of the volume of postheparin plasma was used in the usual assay. Figure 2 shows the time course studies conducted in seven of 22 control children. Both lipase activities appeared in plasma very fast and reached maxima at $5 \mathrm{~min}$ after heparin injection. From this, clinical samples of postheparin plasma were collected $5 \mathrm{~min}$ after administration of heparin. Serum TG and TC were measured enzymatically and HDL-C was determined after precipitation by phosphotungstic acid (3). Serum immunoreactive insulin was measured by a commercial kit (Amersham, Buckinghamshire, England). All data are presented as mean \pm SEM. Statistical evaluation was performed by analysis of variance and by the least squares linear regression analysis.

\section{RESULTS}

Serum lipid levels in the patients. The mean \pm SEM values of serum TG, TC, and HDL-C for the six groups of children are 


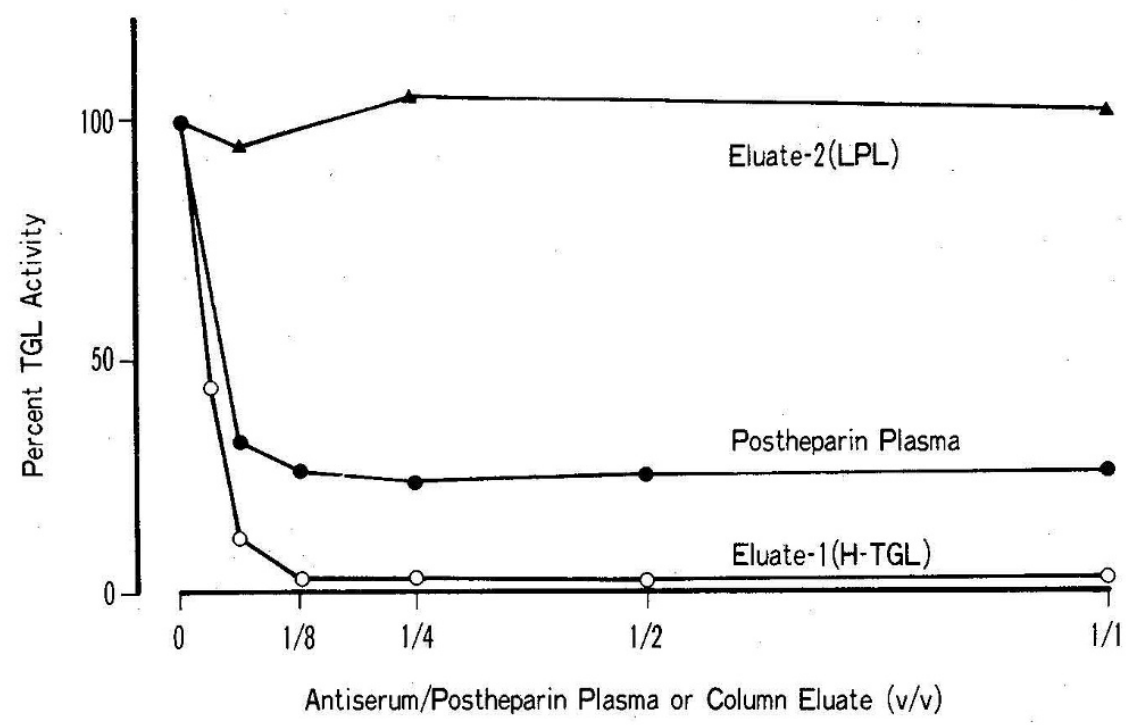

Fig. 1. Effects of different amounts of antiserum on the lipolytic activities of postheparin plasma (๑) and LPL (A) and HTGL (O) purified by heparin-Sepharose affinity chromatography.
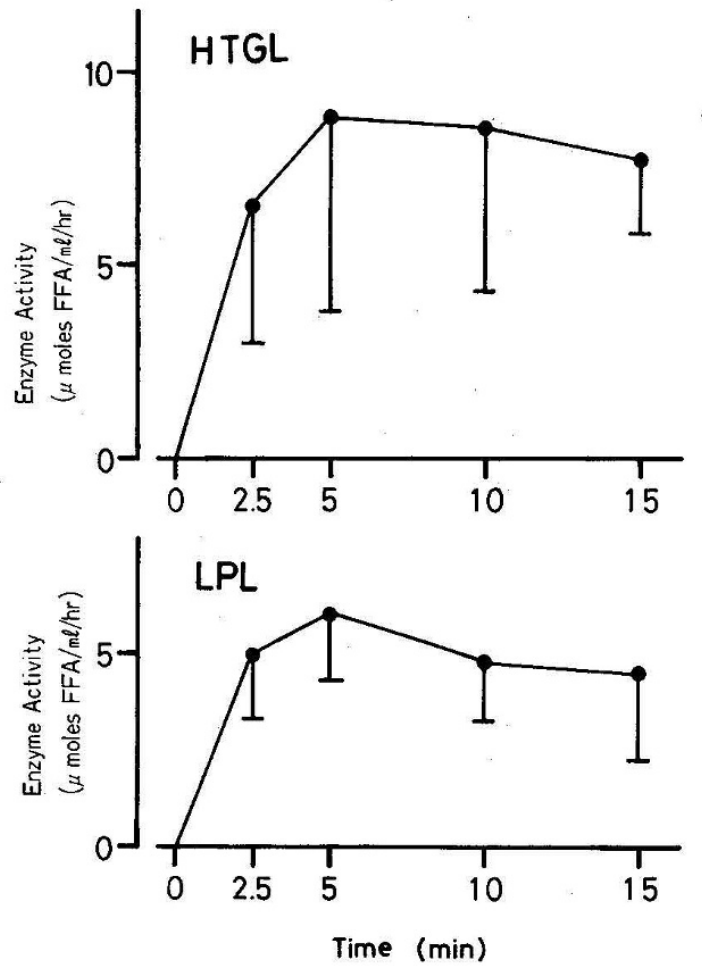

Fig. 2. Time course of the changes in plasma lipase activities after IV administration of heparin (10 U/ $\mathrm{kg}$ body weight) in seven nonobese, normolipidemic children.

summarized in Table 1. In each group, TG level was significantly higher than in controls $(P<0.001)$. The serum TG level in Tx was lower than those in HD $(P<0.01)$ and CRF III $(P<0.02)$. Although the serum TC levels in Tx and HD were similar to controls, those for patients in CRF groups I $(P<0.01)$, II $(P<$ $0.01)$, and III $(P<0.02)$ were higher than in controls. Serum HDL-C level in Tx and CRF I were similar to controls, while those in CRF II $(P<0.01)$, HD $(P<0.001)$, and CRF III $(P<$ $0.001)$ were lower than in controls. The HDL-C value was higher in Tx than in HD $(P<0.001)$ CRF II $(P<0.05)$ and CRF III $(P<0.01)$. In all patients, there was an inverse correlation between serum TG and HDL-C levels $(r=0.441 ; P<0.01$; Fig. $3 a$ ). Neither serum TG nor TC levels were correlated with $\mathrm{C}_{\mathrm{cr}}$, whereas the serum HDL-C levels in Tx and in CRF I, II, and III
$0.523 ; P<0.01 ;$ Fig. $3 b$ ). Serum lipid levels were not related to the dose of steroid in the Tx patients.

Postheparin plasma lipase activities. The LPL and HTGL activities in postheparin plasma of six groups of children are shown in Table 1 . The LPL activities in HD $(P<0.001)$, CRF II $(P<0.05)$, and CRF III $(P<0.01)$ were lower than that in controls, whereas those in Tx and CRF I were similar to that in controls. Although the HTGL activity was not significantly decreased in any of the five groups of patients, it was positively correlated with the logarithmic value of $\mathrm{C}_{\mathrm{cr}}$ in CRF I, II, and III $(r=0.659 ; P<0.005$; Fig. 4$)$, as well as Tx $(r=0.768 ; P<$ 0.025 ; Fig. $3 c$ ). There was no apparent direct relationship between either LPL or HTGL activity and any of the individual serum lipids measured (TG, TC, HDL-C).

Serum insulin levels. The fasting serum insulin levels and the insulin areas under the curve in response to the oral glucose tolerance test for the patients are summarized in Table 2 . The fasting serum insulin level in Tx was higher than in $\mathrm{HD}(P<$ $0.01)$ and CRF I $(P<0.05)$, II $(P<0.05)$, and III $(P<0.05)$. Similarly, the total insulin release (as indicated by the area under the curve) in Tx was higher than in HD $(P<0.01)$ and CRF I $(P<0.05)$, II $(P<0.05)$, and III $(P<0.01)$. The serum insulin area did not correlate with $\mathrm{C}_{\mathrm{cr}}$ or with the dose of steroid in $\mathrm{Tx}$. In the patients of the other four groups who were not receiving steroid therapy, the serum insulin area was not positively correlated with but rather showed a weak inverse correlation with serum TG level $(r=-0.473 ; P<0.05$; Fig. $3 d)$.

\section{DISCUSSION}

Hyperlipidemia is common in both adults (13) and children (21) with CRF and renal allograft recipients. From the studies in adults, it has been postulated that the impaired catabolism of triglyceride-rich lipoprotein due to a selective decrease in either LPL $(10)$ or HTGL $(2,16)$ or both $(1,7,12)$ is a contributing factor to the hypertriglyceridemia in patients with CRF. On the other hand, several reports suggest that overproduction of TG may also contribute to uremic hypertriglyceridemia $(5,6,19$, 22). Papadopoulou et al. (20) have reported that hyperlipidemia occurred early in the course of CRF in children, and that hypertriglyceridemia increased as renal function deteriorated.

It has been proposed that lipase activities and insulin levels may contribute differentialy to the hyperlipidemia observed in patients with chronic renal failure treated conservatively and those treated actively. We will consider comparisons of lipid profiles, lipase activities, and finally insulin concentrations between groups. 
Table 1. Mean \pm SEM values of serum lipids and postheparin plasma lipase activities in study subjects*

\begin{tabular}{|c|c|c|c|c|c|c|c|}
\hline Group & $n$ & Age (yr) & $\begin{array}{c}\mathrm{TG} \\
(\mathrm{mg} / \mathrm{dl})\end{array}$ & $\begin{array}{c}\mathrm{TC} \\
(\mathrm{mg} / \mathrm{dl})\end{array}$ & $\begin{array}{l}\text { HDL-C } \\
(\mathrm{mg} / \mathrm{dl})\end{array}$ & $\begin{array}{c}\mathrm{LPL} \\
(\mu \mathrm{mol} \mathrm{FFA} / \mathrm{ml} / \mathrm{h})\end{array}$ & $\begin{array}{c}\text { HTGL } \\
(\mu \mathrm{mol} \mathrm{FFA} / \mathrm{ml} / \mathrm{h})\end{array}$ \\
\hline$T x$ & 9 & $13 \pm 1$ & $174 \pm 17^{a}$ & $192 \pm 14$ & $66 \pm 5$ & $4.17 \pm 0.60$ & $6.78 \pm 1.22$ \\
\hline HD & 9 & $11 \pm 1$ & $270 \pm 31^{a, e}$ & $188 \pm 23$ & $36 \pm 4^{a, f}$ & $2.99 \pm 0.45^{a}$ & $4.45 \pm 1.21$ \\
\hline CRF I & 3 & $11 \pm 1$ & $242 \pm 48^{a}$ & $253 \pm 25^{b}$ & $56 \pm 6$ & $4.33 \pm 0.85$ & $9.29 \pm 0.49$ \\
\hline CRF II & 7 & $12 \pm 1$ & $209 \pm 34^{a}$ & $231 \pm 30^{b}$ & $50 \pm 6^{b . g}$ & $3.80 \pm 0.57^{c}$ & $6.37 \pm 0.54$ \\
\hline CRF III & 8 & $10 \pm 1$ & $254 \pm 58^{a, h}$ & $217 \pm 17^{d}$ & $47 \pm 3^{a, e}$ & $3.8 \pm 0.74^{b}$ & $4.21 \pm 0.95$ \\
\hline Controls & 22 & $9 \pm 1$ & $68 \pm 5$ & $165 \pm 5$ & $69 \pm 4$ & $5.21 \pm 0.29$ & $6.38 \pm 0.56$ \\
\hline
\end{tabular}

* Tx, patients after renal transplantation $\left(\mathrm{C}_{\mathrm{cr}} \geqq 20 \mathrm{ml} / \mathrm{min} / \mathrm{m}^{2}\right)$. HD, patients on maintenance hemodialysis. FAA, free fatty acids. CRF I, CRF II, and CRF III, conservatively treated patients with chronic renal failure (CRF I, $\mathrm{C}_{\mathrm{cr}} \geqq 20 ; \mathrm{CRF}$ II, $\left.6 \leqq \mathrm{C}_{\mathrm{cr}}<20 ; \mathrm{CRF} \mathrm{III}, \mathrm{C}_{\mathrm{cr}} \leqq 5 \mathrm{ml} / \mathrm{min} / \mathrm{m}^{2}\right)$. ${ }^{a} P$ $<0.001,{ }^{b} P<0.01,{ }^{c} P<0.05,{ }^{d} P<0.02$ (as compared with controls); ${ }^{e} P<0.01,{ }^{f} P<0.001,{ }^{g} P<0.05,{ }^{h} P<0.02$ (as compared with Tx).
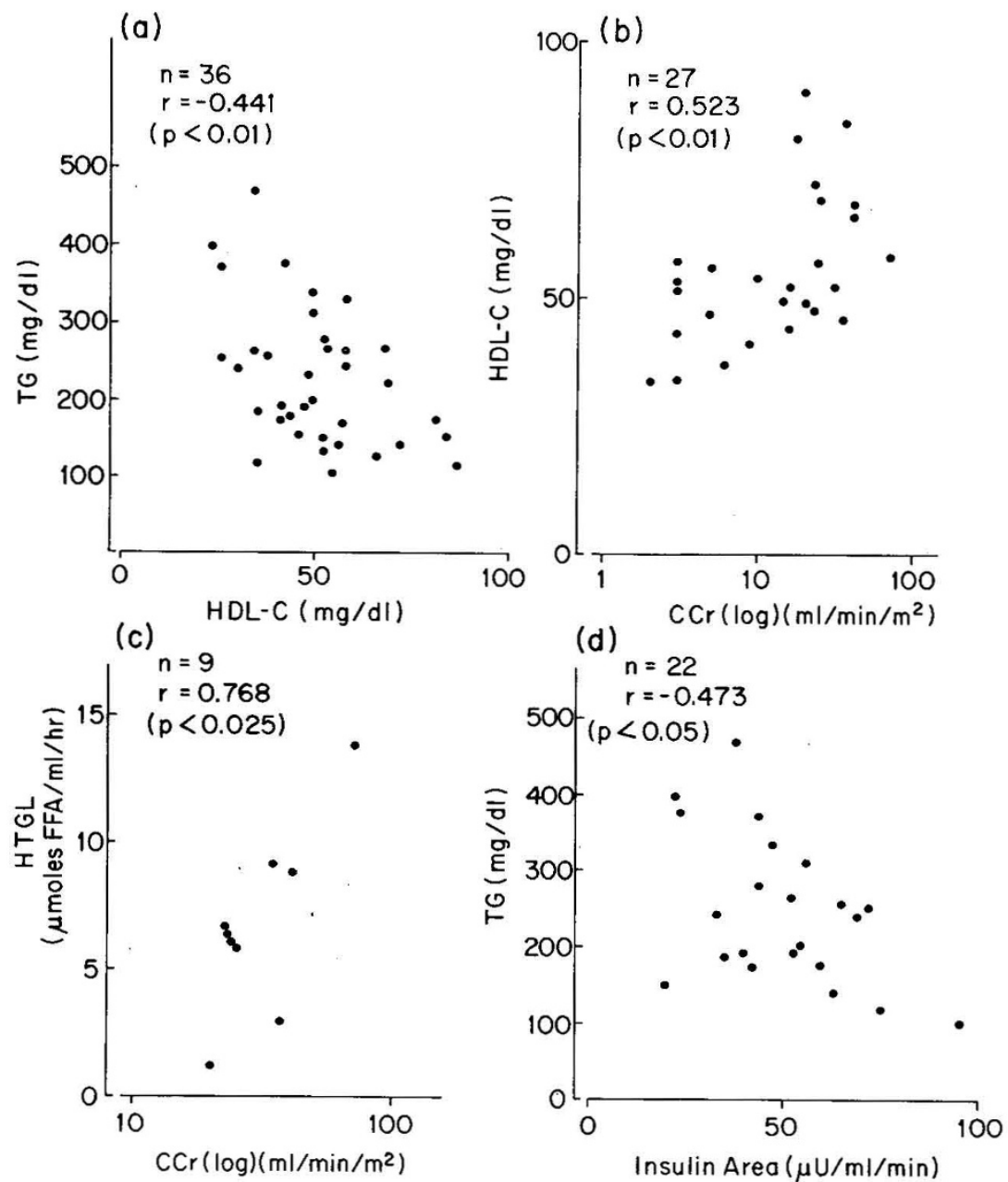

Fig. 3. Relationships between: ( $a$ ) serum triglyceride and HDL-cholesterol concentrations in all patients, $(b)$ serum HDL-cholesterol concentration and the logarithmic value of endogenous creatinine clearance in conservatively treated patients and transplant recipients, $(c)$ postheparin plasma HTGL activity and the logarithmic value of endogenous creatinine clearance in the transplanted patients, and $(d)$ serum triglyceride concentration and serum insulin area under challenge in conservatively treated and hemodialyzed patients.

failure, all patients had hypertriglyceridemia including hemodialyzed patients and transplant recipients, whereas the total cholesterol level was significantly elevated only in those patients treated conservatively. The patients with more severe renal failure had the lower HDL-C levels. Similarly, those with severe renal failure had low LPL and HTGL activities. The hypertriglyceridemia and the decreased HDL-C level in CRF reported in this study confirm the results of previous studies in children (20) and adults (16). The inverse correlation between serum TG and HDL-C levels in our patients was in keeping with the view that low HDL-C levels in hypertriglyceridemic states are the result of reduced TG metabolism (18).

Of most interest are the data on HTGL and LPL activities in these patients. As shown in Fig. 4, there is a significant positive correlation between creatinine clearance and HTGL activity in patients with CRF conservatively treated (CRF I-III). Similar correlation was also observed in transplant recipients, treated as a separate group (Fig. 3c). That is, the lower HTGL levels were observed in those patients with the most severe renal failure (CRF III and HD; Fig. 4). Similarly, the LPL activity was low in those patients with severe renal failure. Utilization of the data limited to those presented here did not show a significant correlation between creatinine clearance and LPL activity. However, such a positive correlation was observed when additional patients were added. (These patients were not included in the full study due to incomplete data but did have LPL and $\mathrm{C}_{\mathrm{cr}}$ assays.) Thus, 


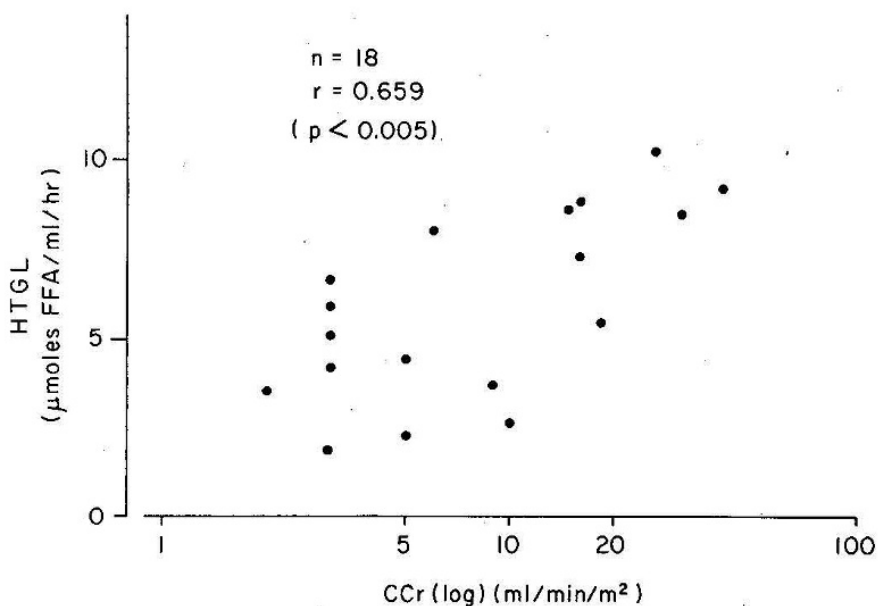

Fig. 4. Relationship between postheparin plasma HTGL activity and the logarithmic value of endogenous creatinine clearance in patients with conservatively treated chronic renal failure.

Table 2. Mean \pm SEM values of serum insulin levels in patients

\begin{tabular}{llcc}
\hline & & \multicolumn{2}{c}{ Serum insulin level } \\
\cline { 3 - 4 } Group & $n$ & Fasting $(\mu \mathrm{U} / \mathrm{ml})$ & Area $(\mu \mathrm{U} / \mathrm{ml} / \mathrm{min})$ \\
\hline TX & 7 & $27 \pm 5$ & $127 \pm 35$ \\
HD & 8 & $14 \pm 2 *$ & $52 \pm 7 \dagger$ \\
CRF I & 2 & $11 \pm 2 \ddagger$ & $38 \pm 18 \ddagger$ \\
CRF II & 5 & $14 \pm 5 \ddagger$ & $56 \pm 12 \ddagger$ \\
CRF III & 7 & $15 \pm 2 \ddagger$ & $47 \pm 4 \dagger$ \\
\hline
\end{tabular}

$$
\begin{aligned}
& { }^{*} P<0.02 . \\
& \dagger P<0.01 \text { (as compared with Tx). } \\
& \ddagger P<0.05 \text {. }
\end{aligned}
$$

both lipase activities tended to decrease as renal function deteriorated in patients conservatively treated. In contrast, although transplant recipients maintained mild hypertriglyceridemia, they had normal lipase activities.

There is a possibility that repeated administration of heparin in HD patients may be a factor in the observed abnormality of postheparin plasma lipase activities in this group. However, Huttunen et al. (12) have reported that lipase activities were not affected by hemodialysis in his patients, nor were these activities affected by intermittent heparin administration at 2-day intervals in healthy adults. Thus, it is likely that the decrease of LPL activity in HD patients is due to the metabolic derangement of uremia rather than heparin-induced depletion. It would appear that the observed decrease of both lipase activities is the result of impaired renal function and that decreased LPL activity and, possibly, decreased HTGL activity contribute to uremic hypertriglyceridemia. Further, the data indicate that these changes can be partially reversed by transplantation.

Comparison of plasma insulin concentrations (basal and stimulated) between conservatively treated patients and those treated with transplantation revealed significantly higher insulin levels in the latter group. That is, the transplant recipients had hypertriglyceridemia with normal lipase activities but higher insulin levels than in the conservatively treated group. Thus, in the group of children with transplanted kidneys, the mild hypertriglyceridemia observed may be due to hyperinsulinism leading to overproduction of triglyceride. However, as these patients were treated with steroids, the observed effects could be partly due to this therapy $(4,14)$.

There are several reports in adults suggesting that overproduction of TG may lead to hypertriglyceridemia in renal failure (5, $6,19,22)$. Some studies also suggest that hyperinsulinemia may contribute to this hypertriglyceridemia $(5,22)$. It has been also demonstrated that hyperinsulinemia or glucose intolerance due to insulin resistance occurs in older patients with uremia (8). These abnormalities may cause both an increase in hepatic TG secretion and a decrease in TG removal. In some of these reports, a positive correlation between the degree of hyperinsulinemia and triglyceride level was observed. However, no such comprehensive data have been reported in children, although it has been reported that fasting insulin levels were elevated in children on hemodialysis (9).

Neither LPL nor HTGL activity was statistically correlated with any of the individual serum lipid levels measured. It has been reported both in adults (19) and children (20) that the hypertriglyceridemia occurs early in the course of renal insufficiency. In the present study, hypertriglyceridemia was observed even in patients with mild renal failure who had normal lipase activities. In such patients, other factors may be responsible for the development of hypertriglyceridemia (23).

In conclusion, decrease of lipase activity may contribute to hypertriglyceridemia in patients with conservatively treated severe renal failure, while overproduction of triglyceride due to hyperinsulinemia rather than a defective triglyceride removal may be a factor for the hypertriglyceridemia in transplant recipients. Hyperlipidemia in mild renal failure in the absence of detectable anomalies in lipase activities or insulin levels suggests the presence of other etiological factors in this group of patients.

\section{REFERENCES AND NOTES}

1. Applebaum-Bowden DM, Goldberg AP, Hazzard WR, Sherrard DJ, Brunzell JD, Huttunen JK, Nikkilä EA, Ehnholm C 1979 Postheparin plasma triglyceride lipases in chronic hemodialysis. Metabolism 28:917

2. Bolzano K, Krempler F, Sandhofer F 1978 Hepatic and extrahepatic triglyceride lipase activity in uremic patients on chronic hemodialysis. Eur J Clin Invest 8:289

3. Burstein M, Scholnich HR 1973 Lipoprotein-polyanion-metal interactions. Adv Lipid Res 11:67

4. Cattran DC, Steiner G, Wilson DR, Fenton SSA 1979 Hyperlipidemia after renal transplantation: natural history and pathophysiology. Ann Intern Med 91:554

5. Chan MK, Varghese Z, Persaud JW, Baillod RA, Moorhead JF 1982 Hyperlipidemia in patients on maintenance hemo- and peritoneal dialysis. Clin Nephrol 17:183

6. Cramp DG, Tickner TR, Beale DJ, Moorhead JF, Willis MR 1977 Plasma triglyceride secretion and metabolism in chronic renal failure. Clin Chim Acta 76:237

7. Crawford GA, Savdie E, Stewart JH 1979 Heparin-released plasma lipases in chronic renal failure and after renal transplantation. Clin Sci 57:155

8. DeFronzo RA, Alvestrand A 1980 Glucose intolerance in uremia: site and mechanism. Am J Clin Nutr 33:1438

9. El-Bishti M, Counahan R, Jarrett RJ, Stimmler L, Wass V, Chantler C 1977 Hyperlipidemia in children on regular hemodialysis. Arch Dis Child 52:932

10. Goldberg AP, Applebaum-Bowden DM, Bierman EL, Hazzard WR, Haas LB, Sherrard DJ, Brunzell JD, Huttunen JK, Ehnholm C, Nikkilä EA 1979 Increase in lipoprotein lipase during clofibrate treatment of hypertriglyceridemia in patients on hemodialysis. N Engl J Med 301:1073

11. Hibi I, Ishiki G, Egi S, Kitagawa T, Takada G, Tanae A, Takeda A, Tsuchiya Y, Teshirogi T, Matsuura N, Maruyama H, Miki E, Mimura G, Watanabe N, Mano T 1979 Diagnosis of childhood diabetes mellitus and standardization of oral glucose tolerance test. Acta Pediatr Jpn 83:1499 (in Japanese)

12. Huttunen JK, Pasternack A, Vävttinen T, Ehnholm C, Nikkilä EA 1978 Lipoprotein metabolism in patients with chronic uremia. Acta Med Scand 204:211

13. Ibels LS, Reardon MF, Nestel PJ 1976 Plasma post-heparin lipolytic activity and triglyceride clearance in uremic and hemodialysis patients and renal allograft-recipients. J Lab Clin Med 87:648

14. Ibels LS, Alfrey AC, Weil R 1978 Hyperlipidemia in adult, pediatric and diabetic renal transplant recipients. Am J Med 64:634

15. Laskarzewski PM, Morrison JA, Gutai J, Orchand T, Khoury PR, Glueck CJ 1983 High and low density lipoprotein cholesterols in adolescent boys. Metabolism 32:262

16. Mordasini R, Frey F, Flury W, Klose G, Greten H 1977 Selective deficiency of hepatic triglyceride lipase in uremic patients. N Engl J Med 297:1362

17. Murase T, Yamada N, Ohsawa N, Kosaka K, Morita S, Yoshida S 1980 Decline of postheparin plasma lipoprotein lipase in acromegalic patients. Metabolism 29:666

18. Nikkilä EA, Taskinen MR, Kekki M 1978 Relation of plasma high-density lipoprotein cholesterol to lipoprotein-lipase activity in adipose tissue and skeletal muscle of man. Atherosclerosis 29:497

19. Norbeck $H E$, Rössner $S 1982$ Intravenous fat tolerance test with intralipid in chronic renal failure. Acta Med Scand 211:69

20. Papadopoulou ZL, Sandler P, Tina LU, Jose PA, Calcagno PL 1981 Hyperlipidemia in children with chronic renal insufficiency. Pediatr Res 15:887

21. Pennisi AJ, Heuser ET, Mickey MR, Lipsey A, Malekzadeh MH, Fine RN 
1976 Hyperlipidemia in pediatric hemodialysis and renal transplant patients. Am J Dis Child 130:957

22. Reaven GM, Swenson RS, Sanfelippo ML 1980 An inquiry into the mechanism of hypertriglyceridemia in patients with chronic renal failure. Am J Clin Nutr 33:1476

23. Russell GI, Davies TG, Walls J 1980 Evaluation of the intravenous fat tolerance test in chronic renal disease. Clin Nephrol 13:282
24. Schotz MC, Garfinkel AS, Huebotter RJ 1970 A rapid assay for lipoprotein lipase. J Lipid Res 11:68

25. The authors gratefully acknowledge Professor Ian M. Burr (Department of Pediatrics, Vanderbilt University) for his critical review and valuable advice. 26. Address correspondence to Kohtaro Asayama, M.D., Department of Pediatrics, Vanderbilt University Medical School, Nashville, TN 37232.

27. Received for publication September $28,1983$.

\section{Erratum}

Vol. 18, p. 682, Letter to the Editor, P. Eggert and C. Stick.

Waverly Press regrets that it omitted the affiliation of these authors, which is Institut für angewandte Physiologie und medinizinische Klimatologie der Universität Kiel, Olshausenstrasse 40-60, Geb. C2, D-2300, Kiel, Federal Republic of Germany.
The following article, which appears on pages 789-794, was originally published in the July 1984 issue (Vol. 18, No. 7) on pages 684-689.

Because the article was not cited in the Table of Contents, it has been reprinted in its entirety. The publisher regrets the error. 